\section{Cetrimide allergy presenting as suspected non-accidental injury}

Suspected non-accidental injury is becoming a more frequent paediatric diagnosis in Britain. I describe a case of presumed non-accidental injury that proved to be an allergic response to cetrimide (12\% solution), a commonly prescribed preparation.

\section{Case report}

A 20-month-old boy was admitted to the paediatric ward after presenting to casualty with a large burn on the right pectoral area (figure). He was the product of a normal pregnancy and there was no history of note except a head injury sustained at 15 months. There was no history of allergy. He came from an unstable family background, the mother being unmarried and cohabiting with a man who was not his father.

In the early hours of the morning of admission he had woken screaming, having previously been well. Six hours later a general practitioner had been called to see the child but had found no reason for his behaviour. During the subsequent 10 hours an area of erythema $14 \times 8 \mathrm{~cm}$, including a central area of blistering with bullae formation, developed on the right chest wall. $\mathrm{He}$ presented in the accident and emergency department and was admitted. Because no explanation was forthcoming possible non-accidental injury was diagnosed and a case conference called.

Investigation by the police and social services concluded the lesion to be accidental in origin. Exhaustive inquiry established that shampoo containing cetrimide $12 \%$ had been spilled on to the child's chest, while he was unattended, on the eve of admission.

A control experiment was performed, with the mother's consent, and a small quantity of cetrimide (12\% solution) was applied to the left chest. This produced a lesion identical with the first.

Both lesions were treated with silver sulphadiazine ointment, ' $N$ ' for Burns, and non-adhesive dressings. He made good cosmetic recovery.

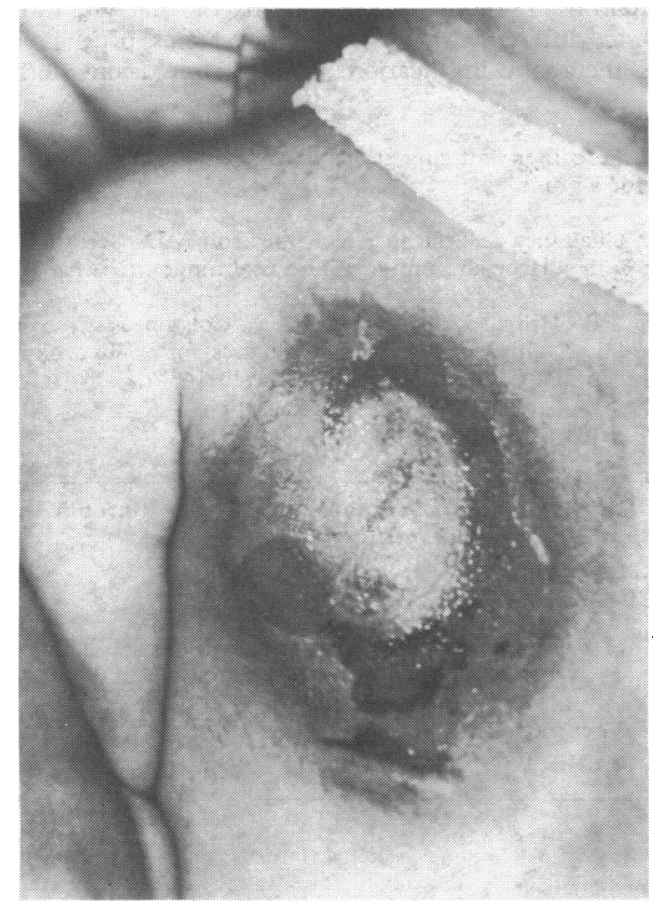

Burn caused by allergic response to cetrimide.

\section{Comment}

Cetrimide is a quaternary ammonium compound. These are common constituents of many sterilising and detergent fluids for skin antisepsis, shampooing hair, and cleaning instruments. They are usually well tolerated, and few reports exist of true allergic contact dermatitis. ${ }^{1-3}$ Indeed, the appearance of this lesion was that of a primary local irritant reaction. In many cases occlusion seems to be the main factor. ${ }^{4}$
This case was particularly fraught in view of the emotional and medicolegal implications for all concerned. Some weeks after discharge the parents alleged in a solicitor's letter that the second burn had been caused without consent. The matter had been fully documented in the notes, and the allegation was therefore refuted completely. Thus the importance of full, impartial, and prompt investigation and documentation of all similar cases cannot be overemphasised, and we are reminded of the potential hazards of commonly used pharmaceutical and domestic preparations.

I thank Dr D M Morgan, consultant paediatrician, Airedale General Hospital, Steeton.

${ }^{1}$ Imperial Chemical Industries. Antiseptics in practice. Macclesfield: ICI, 1978.

2 Sharvill D. Reaction to chlorhexidine and cetrimide. Lancet $1965 ; \mathrm{i}: 771$.

${ }^{3}$ Haidar $Z$. An adverse reaction to a topical antiseptic (cetrimide). $\mathrm{Br} \mathcal{F}$ Oral Surg 1977;15:86-91.

4 August PJ. Cutaneous necrosis due to cetrimide application. $\mathrm{Br} \mathrm{Med} \mathcal{f}$ $1975 ; \mathrm{i}: 70$.

(Accepted 30 October 1981)

Airedale General Hospital, Steeton, West Yorkshire

JOHN K INMAN, MB, CHB, senior house officer

\section{Pruritus after administration of hetastarch}

Hetastarch (hydroxyethyl starch) is widely used as a sedimenting agent to increase yields of granulocytes during leucapheresis. We report four cases in which severe pruritus occurred after administration of hetastarch, causing considerable discomfort to the previously healthy volunteer donors. The pruritus lasted for three to six months.

\section{Case reports}

Severe pruritus developed in four healthy male donors (including three of us) shortly after they had given granulocytes on an IBM cell separator. The cases occurred at three different centres over a four-month period. As part of the procedure the donors received hetastarch as a $6 \%$ solution (Plasmasteril). One donor received one litre over two successive days, the others two litres over seven days; all donated granulocytes on two or three occasions. Two of the donors received hydrocortisone $200 \mathrm{mg}$ intravenously immediately before donation. None had a history of allergy.

The donors developed itching some two weeks after the procedure. The itching was generalised or worse in the perineal region. It was exacerbated by warm water, exercise, scratching, or rubbing with towels. Cold water and cool lotions were soothing. The itching was extremely uncomfortable and socially embarrassing. There were no visible skin changes, and the itching subsided slowly over three to six months. One donor subsequently received a further $500 \mathrm{ml}$ infusion of hetastarch when donating granulocytes but experienced only a short-lived and less severe recurrence of symptoms. At the time of this donation, six months after the initial occasion, the itching had settled and the association with leucapheresis had not been made.

\section{Comment}

Sedimenting agents increase the yield of granulocytes, and hetastarch seemed particularly suited for this purpose because it was thought not to be antigenic in man. ${ }^{1}$ Few major problems have been associated with its use, although a case of lichen planus was recently reported in a donor exposed to it. ${ }^{2}$

We believe that the hetastarch used during leucapheresis was responsible for the itching in our cases. We recognise that other causes-for example, leaching of plasticisers from the equipmentare possible, but they are less likely since itching has occurred only after granulocyte collection and has not affected patients receiving regular plasma exchanges without hetastarch.

Hetastarch is excreted by the kidneys and is also taken up into the reticuloendothelial system. It is an alarmingly persistent substance 